\title{
CONSIDERAÇÕES SOBRE A RELAÇÃO ENTRE MORALIDADE E VIDA EM KANT*
}

\author{
Alexandre Medeiros de Araújo ${ }^{* *}$
}

\section{Resumo}

O texto tem por objetivo defender a proposta kantiana para a moralidade da acusação de ser ela uma moralidade "abstrata", "vazia", "fria", em função de seu princípio formal. Segundo aquela maneira de ver a moralidade kantiana, essa proposta não teria nenhuma conexão com a vida efetiva dos seres humanos. Para defender a proposta kantiana contra essa acusação, serão levados em conta os elementos presentes na concepção de razão proposta por Kant e o modo como operam as faculdades na motivação moral. Segundo a concepção kantiana, a relação de determinação da vontade pela razão ocorre de uma maneira dinâmica entre as faculdades, razão e vontade, que se afinam em função de um fim da razão. Esse fim é a própria realização da virtude. A sua realização gera, por sua vez, um sentimento vivificador no ânimo do ser humano: o sentimento de respeito pela humanidade em cada pessoa como "fim em si". O texto pretende argumentar que esse é um dos caminhos pelos quais podemos vislumbrar a proposta da moral kantiana para além do mero "formalismo vazio". Ele chama, também, a atenção para aquilo que, na relação entre a lei moral e a vontade humana, configura a "força motriz" e "comoção" da moralidade em relação a essa mesma vontade.

Palavras Chave: Humanidade. Kant. Moralidade. Motivo. Respeito. Ânimo.

\begin{abstract}
The paper aims at defending Kantian ethics against the criticism of being "abstract", "void", and "without sentiment". The criticism emerges from the fact that Kant grounds his ethics in a formal rather than a material principle. According to this criticism, Kant's ethics would not relate to real human life. This paper, however, will not only consider the different faculties present in human reason, but also the way these faculties act upon moral motivation. In this motivation, the will is dynamically determined by reason in view of the realization of reason's end, which is the achievement of virtue. This achievement of virtue generates, in turn, a vivid feeling in the soul: the feeling of respect each person has for humanity as an end in itself. The text argues that this is one of the ways by means of which Kant's ethical proposal goes beyond the assumption of "void formalism". It also acknowledges the roles of "vital force" and "commotion" in the achievement of the moral law.
\end{abstract}

\footnotetext{
* Gostaria de agradecer à Professora Vera Cristina de Andrade Bueno e ao Professor Edgard José Jorge Filho os valiosos comentários e sugestões que fizeram a uma versão anterior deste trabalho.

${ }^{* *}$ Doutorado em Filosofia pela PUC-Rio e Professor do Instituto Federal de Educação, Ciência e Tecnologia do Rio Grande do Norte. E-mail: alexandre.medeiros@ifrn.edu.br. CV: http://lattes.cnpq.br/5218699423128273
} 
Key words: Humanity. Kant. Morality. Reason. Respect. Soul.

\section{INTRODUÇÃO}

De um modo geral, podemos dizer que há várias maneiras de se compreender a filosofia. Segundo o seu conceito escolástico, ou seja, do ponto de vista das escolas, ela é, de acordo com Kant, "o sistema dos conhecimentos filosóficos ou dos conhecimentos racionais a partir de conceitos" (Lógica; A 23, p. 41). Por outro lado, e diferente desse sentido escolástico, a filosofia, por referir-se "aos fins últimos da razão humana”, é compreendida como sendo uma "sabedoria prática", e, por isso mesmo, diretamente vinculada à vida do ser humano. Desse ponto de vista, a filosofia é chamada, de acordo com Kant, de "cosmopolita" ou a "filosofia segundo o seu conceito de mundo" (Lógica; Ak 24, p. 41).

Poderíamos dizer que a filosofia considerada desse último ponto de vista é a que figura como o horizonte em face do qual se movimenta toda a filosofia crítica de Kant. Nesse sentido, não seria exagero dizer que a filosofia kantiana tem como objetivo principal esclarecer e chamar a atenção para o papel que a moralidade, enquanto, sabedoria prática, desempenha na vida humana. ${ }^{1}$ Isso equivaleria a dizer que a proposta para a moralidade apresentada por Kant toma um lugar todo especial no conjunto da sua filosofia crítica, e, porque não dizer, na própria vida do ser humano. Pois, se levarmos em conta o fato de Kant considerar o conceito de liberdade como sendo o "fecho de abóboda" "de todo o edifício de um sistema da razão pura"2 e se tal conceito é a própria ratio essendi (razão de ser) da moralidade, então é plausível que se admita, com isso, que o maior interesse que a razão humana pode manifestar, consiste naquilo que diz

\footnotetext{
${ }^{1}$ Na Lógica (Jäsche), Kant define o sentido da filosofia segundo o seu conceito de mundo como a "ciência dos fins últimos da razão humana. Este conceito altivo confere dignidade, isto é, um valor absoluto, à Filosofia". Mais adiante, Kant afirma que a filosofia desse ponto de vista "visa a utilidade" e é considerada uma doutrina da sabedoria: a legisladora da razão, e nesta medida o filósofo não é um artista da razão, mas um legislador. [...] O filósofo prático, o mestre da sabedoria pela doutrina e pelo exemplo, é o filósofo propriamente dito. Pois a Filosofia é a ideia de uma sabedoria perfeita que nos mostra os fins últimos da razão humana" (Lógica, A 24, p. 41).

${ }^{2}$ KANT, I. Crítica da razão prática. Tradução: Valério Rohden. São Paulo, Martins Fontes, 2003, A 4. A letra $\mathrm{A}$ indica que a tradução é feita a partir da edição $\mathrm{A}$. As próximas referências a esse livro serão feitas por meio das iniciais $C R P r$, seguidas primeiramente do número da página da edição $\mathrm{A}$ e do número da página da tradução para a língua portuguesa.
}

DIALEKTIKÉ, v. 1, novembro 2014, p. 29-49

Artigo submetido e aceito em outubro/2014 
respeito à moralidade ${ }^{3}$. É nesse sentido que a proposta kantiana para a moralidade é um dos caminhos pelos quais podemos lidar com assuntos que, por se referirem diretamente aos interesses da nossa razão, não podemos abrir mão.

Todavia, a proposta kantiana para a moralidade ainda não foi explorada em toda a sua dimensão. Uma prova disso se encontra exatamente nas críticas que ela vem recebendo desde os seus contemporâneos até os dias atuais como sendo uma ética fundada metafisicamente ${ }^{4}$, cujo princípio, por ser um princípio formal, seria, em função disso, "vazio", "abstrato" e, portanto, distante da vida efetiva dos seres humanos.

Talvez não seja tão considerada, quando se trata dos elementos concernentes à lei moral, a passagem da Crítica da faculdade do juízo (1790) $)^{5}$, na qual Kant compara o "entusiasmo" com que o povo judeu vivia a lei mosaica, em sua proibição da produção de imagens, com o sentimento de "comoção" e de "força motriz" que a lei moral comporta ao derrogar as influências das inclinações. Cito Kant:

Talvez não haja no Código Civil dos judeus nenhuma passagem mais sublime que o mandamento: "Tu não deves fazer-te nenhuma efígie nem qualquer prefiguração, quer do que está no céu ou na terra ou sob a terra" etc. Este mandamento por si só pode explicar o entusiasmo que o povo judeu em seu período civilizado sentia por sua religião quando se comparava com outros povos, ou aquele orgulho que o maometismo inspirava. Precisamente o mesmo vale também acerca da representação da lei moral e da disposição à moralidade em nós. É uma preocupação totalmente errônea supor que, se a gente se priva de tudo o que ela pode recomendar aos sentidos, ela então não comporte senão uma aprovação fria e sem vida e nenhuma força motriz ou

\footnotetext{
3 Segundo Allison, a filosofia crítica de Kant pode ser considerada uma "filosofia da liberdade" (ALLISON, Henry. Kant's theory of freedom. Cambridge: Cambridge University Press, 1990, p.1). E, segundo Carnois, "a ideia de liberdade ocupa um lugar privilegiado na filosofia de Kant" (CARNOIS, Bernard. La cohérence de la doctrine kantienne de la liberte. L'ordre philosophique. Paris, Éditions Du Seuil, 1976, p. 11).

${ }^{4}$ A despeito das críticas à metafísica, segundo o Professor Guido de Almeida, o seu descrédito "não é apanágio de nossos tempos. Ele vem de longe e, na verdade, ninguém mais do que Kant contribuiu para ele com sua crítica das pretensões metafísicas da razão pura". (ALMEIDA, Guido Antônio. "Introdução do tradutor". In: KANT, Immanuel. Fundamentação da metafísica dos costumes. São Paulo: Discurso editorial, 2009, p. 11). O próprio Kant tinha consciência do que significava para a sua ética ser acusada de uma ética metafísica. Segundo Guido, "Kant pretende elaborar seu projeto de uma metafísica moral no quadro do pensamento crítico, e isso significa que sua filosofia moral não pode se basear em suposições metafísicas, mas, ao contrário, que sua metafísica moral (nos dois sentidos do termo 'metafísica' ) tem de ser basear em fundamentos críticos". (Id. Ibidem, p. 13-15).

${ }^{5}$ KANT, Immanuel. Crítica da faculdade do juízo. $2^{\mathrm{a}}$ edição. Trad. Valério Rohden e Antônio Marques. Forense Universitária. Rio de Janeiro, 2005. As citações a essa obra serão feitas com as iniciais do título CFJ - seguidas da letra B, que indica a $2^{\mathrm{a}}$ edição da Academia de Ciências de Berlim, bem como da numeração dessa edição e do número da página da tradução para a língua portuguesa.
}

DIALEKTIKÉ, v. 1, novembro 2014, p. 29-49

Artigo submetido e aceito em outubro/2014 
comoção. Trata-se exatamente do contrário; pois lá onde agora os sentidos nada mais vêem diante de si e a inconfundível e inextinguível ideia da moralidade contudo permanece, seria antes preciso moderar o elã de uma faculdade da imaginação ilimitada para não deixar elevarse até o entusiasmo, como, por medo de debilidade dessas ideias, procurar ajuda para elas em imagens e em um aparato infantil" $(C F J$, B $125 ;$ p. 121).

Essa comparação, ainda que enigmática, nos leva a pensar sobre qual seria o papel e o sentido mais profundo de a lei moral poder determinar a vontade humana e como essa acolheria tal determinação. Não obstante as críticas muitas vezes feitas à concepção da lei moral kantiana e à ética do dever, decorrente daquela concepção, se levarmos em conta todos os elementos presentes no conceito de moralidade, que têm relação com a vontade humana, teremos elementos suficientes para vislumbrar a dimensão mais profunda presente nessa relação, para além do mero formalismo.

De modo geral, o formalismo com que a moral kantiana foi identificada, é decorrente da ênfase dada pelos seus críticos à primeira seção da Fundamentação da metafísica dos costumes ${ }^{6}$, que corresponderia à tese segundo a qual a fórmula da lei moral, caracterizada por Kant como um "Imperativo Categórico" obrigaria os seres humanos a agir apenas "por dever", seguindo unicamente a fórmula da lei universal, sem levar em consideração os demais elementos presentes em todas as decisões por eles tomadas.

Ao levar em conta apenas a primeira fórmula do Imperativo Categórico apresentada por Kant na primeira seção da Fundamentação da metafísica dos costumes, a saber, a fórmula da Lei Universal ${ }^{7}$ e a sua variante, a fórmula da Lei da Natureza ${ }^{8}$, como sendo as únicas proposições que expressam o princípio da moral do dever - não se considera, por um lado, nem o desenvolvimento da tarefa apresentada por Kant já no Prefácio à essa obra, e que consiste na "busca e estabelecimento do princípio supremo

\footnotetext{
${ }^{6}$ KANT, Immanuel. Fundamentação da metafísica dos costumes. Tradução: Guido Antônio de Almeida. Discurso Editorial e Barcarolla. São Paulo, 2009. As citações a essa obra serão feitas a partir dessa tradução para a língua portuguesa da primeira (1785) e da segunda edição (1786). Utilizaremos a abreviação do título da obra - FMC- seguida da sigla "Ak" com a numeração que indica a pagina da Academia de Ciências de Berlim, seguida, ainda, do número da página da versão traduzida para a língua portuguesa.

${ }^{7}$ FLU: Fórmula da lei universal: "Age apenas segundo uma máxima tal que possas ao mesmo tempo querer que ela se torne lei universal" (FMC; Ak 402; p. 133). As abreviações que ora utilizamos aqui foram sugeridas por Allen Wood, In: Kant. Tradução: Delamar José Volpato Dutra. Porto Alegre: Artmed, 2008, p. 165.

${ }^{8}$ FLN: Fórmula da lei da natureza: "Age como se a máxima de tua ação devesse se tornar por tua vontade uma lei da natureza" ( FMC; Ak 421; p. 215).
}

DIALEKTIKÉ, v. 1, novembro 2014, p. 29-49

Artigo submetido e aceito em outubro/2014 
da moralidade"(FMC A XV; p. 85), nem, por outro lado, a constituição, a partir desse princípio, do sistema de uma metafísica dos costumes.

Os críticos da moralidade kantiana não consideraram essa $\operatorname{tarefa}^{9}$ em sua totalidade, de modo que não levaram em conta as demais fórmulas com as quais Kant caracterizou o princípio da moral ao longo da segunda e terceira seções, como a "fórmula da Humanidade"10 e a "fórmula da Autonomia", por exemplos; nem, muito menos, consideraram o caráter sistemático de toda sua filosofia em geral e de sua proposta da relação existente entre as faculdades humanas, em especial.

Um exemplo disso é a própria crítica de Hegel à ética kantiana como sendo uma ética meramente formal. Segundo a crítica de Hegel à moralidade kantiana, "o dever pelo dever", por ser meramente "vazio", "abstrato", não pode determinar o agir concreto do sujeito encarnado. ${ }^{11}$ Essa crítica à moralidade do dever, portanto, se baseia no argumento de que o Imperativo Categórico, que ordena a vontade a agir por respeito à lei, constitui-se num "vazio formalismo", na medida em que tal imperativo não leva em consideração o conteúdo das máximas particulares, de modo a não permitir que a legislação universal da razão, "passe a determinações de deveres particulares"12.

Parece, então, que Hegel e outros críticos ${ }^{13}$ da moralidade kantiana, que a veem com um "formalismo vazio", não levaram em conta a completude e a proposta de

\footnotetext{
${ }^{9}$ A esse respeito disso, Allen Wood nos fala que: "A primeira caracterização da ética kantiana adotada por seus seguidores e críticos do idealismo alemão foi a de que a ética kantiana era 'formalista'. $\mathrm{O}$ uso desse epíteto é amplamente devido à ênfase enganosa que os leitores de Kant colocam na primeira formulação do princípio moral, às expensas das outras duas formulações, cujo objetivo é precisamente complementar e então remediar tal 'formalismo'." E, mais adiante afirma que, “ [...] os críticos de Kant, erroneamente privilegiando a FLU e virtualmente excluindo a FH e a FA de sua consideração, eles então acusam a teoria kantiana de se satisfazer com um "formalismo vazio". Essa acusação, entretanto, é uma acusação menos à teoria de Kant do que às suas próprias leituras míopes da Fundamentação"(WOOD, Allen; Kant. Tradução: Delamar José Volpato Dutra. Porto Alegre: Artmed, 2008, pp. 166-7). As fórmulas FH e FA serão tratadas a seguir.

${ }^{10} \mathrm{FH}$ : fórmula da humanidade: "Age de tal maneira que tomes a humanidade, tanto em tua pessoa, quanto na pessoa de qualquer outro, sempre ao mesmo tempo como fim, nunca meramente como meio" ( $F M C$; AK 429; pp. 244-5).

${ }^{11}$ HEGEL, G.W.F. Princípios da Filosofia do Direito. Tradução: Orlando Vitorino. Editora Martins Fontes: São Paulo, 1997. É no § 135 que Hegel dirige uma crítica à ética do dever de Kant. Numa nota a esse parágrafo, Hegel nos diz que: "[...] a afirmação do ponto de vista simplesmente moral que não se transforma em conceito de moralidade objetiva reduz aquele progresso a um vão formalismo e a ciência moral a uma retórica sobre o dever pelo dever. Deste ponto de vista, não é possível nenhuma doutrina imanente do dever. [...] Ora, estabelecer que o dever apenas se apresenta como dever e não em vista de um conteúdo, a identidade formal, isso corresponde precisamente a eliminar todo o conteúdo e toda a determinação" (HEGEL, §135[nota]; pág. 119-120 [meu grifo] ).

${ }^{12}$ Id. Ibidem.

${ }^{13}$ Um crítico contemporâneo da ética kantiana é Ernest Tugendhat que apresenta, ao mesmo tempo, uma relação de admiração e de rejeição com respeito à filosofia moral de Kant. Na sua obra "Lições sobre ética", após ter afirmado sua "rejeição do programa de fundamentação de Kant" - uma fundamentação
}

DIALEKTIKÉ, v. 1, novembro 2014, p. 29-49

Artigo submetido e aceito em outubro/2014 
vinculação "final", ou a afinidade, entre as diversas faculdades da razão ao longo de sua obra crítica e mesmo da sua metafísica dos costumes.

É bem sabido que o método da filosofia tal como é caracterizado por Kant, consiste em se tomar a filosofia como um conhecimento a priori por análise dos conceitos. Nesse sentido, as suas obras críticas têm como ponto de partida a análise dos conceitos para, desse modo, lançar as bases ou estabelecer os fundamentos de uma metafísica, tanto da natureza quanto dos costumes. Pois bem, tanto a Fundamentação da metafísica dos costumes quanto a Crítica da razão prática se inscrevem nesse procedimento analítico em função da "busca e estabelecimento" dos fundamentos do princípio moral de uma "metafísica dos costumes".

De fato, ao se tomar a investigação crítica apresentada nessas obras, pelo menos na Primeira Seção da $F M C$ e na "Analítica da razão prática pura" da $C R P r$ como constituindo toda a doutrina moral de Kant, corre-se o risco de acusá-la de mero formalismo, visto que essas partes são dedicadas à tarefa filosófica de análise dos conceitos, que separa os domínios do puro e do empírico, do a priori e do a posteriori, da forma e da matéria, para, desse modo, melhor investigar as condições e fundamentos da possibilidade de se formular juízos morais.

No que se segue procuraremos esclarecer em que medida a visão da moral kantiana como um "formalismo vazio" não corresponde à totalidade da sua filosofia moral. Nossa suposição é que tais acusações não levam em conta o todo da razão e a relação dinâmica presente entre a razão e a vontade, faculdades que, sem deixar de lado o sentimento, estão envolvidas na vivência moral, e nem o conceito sob o qual a proposta kantiana para a moralidade tem o seu apoio que é o conceito de humanidade como "fim em si" e o "fim supremo" da razão que é a virtude.

\section{VONTADE E VIDA: A RELAÇÃO DINÂMICA ENTRE AS FACULDADES E A BUSCA PELO INCONDICIONADO}

De acordo com a proposta kantiana, para que seja possível esclarecer em que medida os conceitos que estão presentes na vivência moral dos seres humanos se

absoluta, e isto desde uma razão posta nas alturas", Tugendhat afirma que a Fundamentação da metafísica dos costumes "é talvez a coisa mais grandiosa que já foi escrita na história da ética, e ele <0 livro> é, pelo menos em suas duas primeiras secções, uma das poucas obras filosóficas significativas de que dispomos" (TUGENDHAT, E. Lições Sobre ética. 5a edição. Trad. Joãosinho Beckenkamp e Cia. São Paulo: Editora Vozes, 2003, p. 99).

DIALEKTIKÉ, v. 1, novembro 2014, p. 29-49

Artigo submetido e aceito em outubro/2014 
relacionam à autonomia dos mesmos é preciso que se leve em conta o modo como opera a razão. Isso nos leva a crer que, se prestarmos a atenção ao modo como as faculdades se relacionam na determinação da vontade pela razão, é possível que o suposto formalismo do qual a proposta kantiana para a vida moral foi - e muitas vezes ainda é acusada, não se sustenta ou é, no mínimo, questionável. Pretendemos ter as condições necessárias para justificar porque a proposta da ética kantiana não se restringe à de uma formalidade distante da vida efetivo do ser humano.

Se considerarmos a filosofia de Kant como uma preocupação de buscar estabelecer os fundamentos legítimos para as esferas do conhecer e do agir, temos, então, de considerar, antes de mais nada, a relação entre as faculdades que possibilitam tais fundamentos ou princípios, pois de acordo com a proposta kantiana de uma filosofia crítica é preciso investigar as condições a priori segundo as quais tais princípios são possíveis.

Na moralidade, as faculdades que estão relacionadas com o querer humano são a razão pura e a vontade. A razão pura é prática na medida em que é capaz de determinar a vontade. Se a razão pura é capaz de determinar a vontade, e, por isso mesmo, ser também prática, isso significa que tem de haver uma afinidade entre essas faculdades. Ou seja, se consideramos nossa razão como tendo unidade, e não como sendo um mero aglomerado de faculdades, podemos também dizer que essa unidade é resultante de uma afinidade existente entre as faculdades e, por conseguinte, de que a razão humana em sua totalidade tem um vínculo efetivo com a vida dos seres humanos. Uma prova disso consiste no fato de que, ao determinar a vontade do ser racional finito, a razão pura é capaz de gerar um "sentimento a priori" o qual pode ser visto como expressão dessa unidade do todo da razão, ou a razão vista como um sistema. Se a razão é um sistema, as faculdades que a constituem bem como os elementos que estão presentes aí, se articulam na razão humana em função de um fim.

Na Metafísica dos Costumes $(1797)^{14}$ cuja introdução leva o título de "Da relação das faculdades da mente humana com as leis morais" (MC, A 211; p.17), o conceito de "fim" é caracterizado por Kant como "um objeto do arbítrio (de um ser racional), por meio de cuja representação este é determinado a uma ação para produzir

\footnotetext{
${ }^{14}$ KANT, Immanuel. Metafísica dos Costumes. Tradução: Clélia Aparecida Martins (1 ${ }^{\mathrm{a}}$ parte); Bruno Nadai, Diego Kosbiau e Monique Hulshof (2 $2^{\mathrm{a}}$ parte). Ed. Vozes. Petrópolis, RJ, 2013. As citações à essa obra serão feitas a partir dessa tradução com as iniciais $M C$ seguida da letra A e da numeração que indica a edição da Academia e com o número da página da tradução para a língua portuguesa.
}

DIALEKTIKÉ, v. 1, novembro 2014, p. 29-49

Artigo submetido e aceito em outubro/2014 
esse objeto" (MC, A 381). Definição muito semelhante a que Kant dá para o conceito de vontade como "a faculdade do mesmo ente de ser, mediante suas representações, causa da efetividade dos objetos destas representações"( $C R P r$, A 16 [nota]; p.29). O conceito de "fim", como o conceito por meio do qual é possível a articulação entre as faculdades em vista de sua unidade sistemática, faz com que o princípio supremo da razão pura prática, ou a lei moral, possa ser considerado como sendo um "fim" para o ser humano que se decidiu a agir em função da lei. Kant chega até mesmo a identificar o conceito de "fim" ao conceito de "vontade" e esse ao conceito de vida: "A faculdade de um ser de agir conforme suas representações chama-se vida" (MC, A 211; p. 17). ${ }^{15}$

A faculdade da vontade, na medida em que "exige a razão para derivar de leis as ações", "nada mais é do que razão prática" ( $F M C$, Ak 412; p.183). Desse modo, se a vida é considerada como sendo vontade, e se a vontade é a razão prática, logo o fím dessa razão como lei prática, se volta necessariamente para a vida do ser humano.

Dito isso, poderíamos tratar da relação entre a lei moral e vontade do ser humano em função de duas vias: a primeira consiste em se tomar a vontade do ser humano, estrito sensu, como uma faculdade que age segundo princípios. Na medida em que possui uma vontade que age em função de princípios, a adoção desses princípios depende de o ser humano poder julgá-los para, então, poder elegê-los como máximas de sua vontade. No ser humano, a faculdade que julga tais princípios é a razão prática que é a faculdade dos princípios. É a razão prática que vai buscar e julgar um princípio que seja incondicionado para a determinação da vontade. ${ }^{16}$

O princípio incondicionado que a razão prática pura realiza em si mesma como um factum, "um ato", é a própria lei moral. A lei moral é um princípio incondicionado da razão prática pura na medida em que, não dependendo de nada fora dela mesma, ou seja, de nenhum móbil da experiência, é uma lei dada pela própria razão, a saber, uma lei da autonomia, da liberdade do ser racional.

Se a razão prática pura é a uma faculdade que contém o princípio de determinação em função do qual a vontade pode ser determinada de maneira a priori, então esse princípio é o princípio com valor incondicional, na medida em que sua causalidade, em relação à vontade, é uma causalidade livre.

\footnotetext{
${ }^{15} \mathrm{Na} C R P r$, Kant define o conceito de "vida" como "a faculdade de um ente de agir segundo leis da faculdade de apetição" ( $C R P r$, A 16, [nota] p. 29).

16 "A razão é uma faculdade dos princípios e caminha para o incondicionado na sua existência mais extrema" (CFJ, B 339).
} 
O ser humano, ainda que seja influenciado pelas inclinações da sua natureza sensível, que são imediatas, tem o poder de agir segundo princípios da razão, isto é, agir com base em um poder que lhe pertence em função de ele ser também dotado de uma faculdade suprassensível (a razão) a partir da qual ele pode considerar-se como sendo livre.

Segundo Kant, o ser humano toma consciência da sua liberdade por meio da consciência da lei moral, que se expressa pela coerção sentida do dever. No entanto, a consciência da lei moral e, com essa, a consciência da liberdade, não se dá de maneira totalmente pura, como se a vontade do ser humano fosse determinada num plano puramente abstrato. Para que seja possível a consciência da lei moral e, por conseguinte, da liberdade, é necessário que essa lei, de algum modo, tenha um contraponto na sensibilidade, do contrário, não faria sentido ao ser humano falar de lei moral como uma lei do dever, ou como um imperativo para a sua vontade. ${ }^{17}$

É verdade que a liberdade enquanto uma ideia da razão ${ }^{18}$ não pode ter um correlato sensível na experiência que confira à essa liberdade uma realidade objetiva, visto que as notas características presentes no conceito de liberdade são incompatíveis com as intuições sensíveis. Todavia, Kant admite que há uma liberdade, chamada de liberdade prática, que se relaciona diretamente com o arbítrio humano e que pode ser “provada pela experiência"(CRP; A 803/B 831). Sabemos por meio da experiência que temos uma vontade livre segundo a qual podemos nos determinar, na medida em que

\footnotetext{
${ }^{17}$ A esse respeito, Fernando Moliner nos diz que: “[...] a vida passional que gira em torno às tendências, inclinações, impulsos, etc., [...] desempenha também um papel fundamental em uma faceta negativa, que completa a valorização positiva que Kant tem adjudicado à formulação moral ditada pelo imperativo categórico. Se trata de que toda a legislação que esta regula ou é assumida pela exigência da universalidade das intenções éticas careceria de sentido se não houvesse um domínio de tendências ou impulsos que deveriam ser submetidos ou sacrificados à instâncias de seu mandato [...]. Esta projeção da razão prática sobre as paixões, as tendências e os motivos empíricos, torna compreensível aquele texto da Crítica da razão pura a qual dizia que 'a liberdade prática pode provar-se por experiência' ". (MOLINE, Fernando Montero: "Libertad y Experiencia: la fundamentacion de la libertad moral em la Critica de la razon pura". In Kant despues de Kant, pp.: 41-2).

${ }^{18}$ Kant justificou a possibilidade e a necessidade de uma causalidade livre num domínio suprassensível a partir da limitação da causalidade sensível ao nível dos fenômenos. Essa causalidade livre, como pura espontaneidade, é também chamada de "liberdade transcendental" que, como uma ideia da razão pura, tem um estatuto regulativo, ou seja, não determina nenhum objeto na experiência. A partir do conceito de uma causalidade livre que opera no registro do suprassensível, foi possível a Kant pensar numa liberdade prática, voltada à determinação positiva das ações humanas, na medida em que, por meio dessa, era possível pensar não apenas numa independência das condições sensíveis (como liberdade negativa), mas também como a possibilidade dos seres humanos se autodeterminarem (liberdade positiva).
}

DIALEKTIKÉ, v. 1, novembro 2014, p. 29-49

Artigo submetido e aceito em outubro/2014 
essa liberdade é desafiada, mas não determinada, pela experiência. De acordo com a definição de Kant:

A liberdade em sentido prático é a independência do arbítrio da necessitação por impulsos da sensibilidade. Pois um arbítrio é sensivel na medida em que é afetado patologicamente (por móveis da sensibilidade); ele se chama animal (arbitrium brutum), se ele pode ser necessitado patologicamente. O arbítrio humano é, com efeito, um arbitrium sensitivum, mas não brutum e, sim, liberum, porque a sensibilidade não torna necessária a sua ação; mas, ao contrário, existe no homem uma faculdade de se determinar por si mesmo independentemente da necessitação por impulsos sensíveis" (CRP; A 534/B 562)[grifos do autor].

A liberdade prática, de acordo com essa definição, tem, por um lado, um aspecto negativo no sentido de o arbítrio humano ser independente das inclinações sensíveis, e, por outro lado, um aspecto positivo que consiste em, no ser humano, o seu arbítrio enquanto livre, ser determinado em função de sua razão. Essa relação de determinação a priori entre as faculdades, contudo, dependeria de que o ser humano pudesse refletir acerca dos princípios que fundamentam suas ações. Portanto, de algo que ele quer porque considera como sendo bom incondicionalmente. De modo que não se trata apenas da adoção de um princípio ou de uma lei vazios ou meramente abstratos, e sim de algo que é adotado em função do valor que esse princípio expressa na vida do ser humano.

Podemos, ainda, comparar a relação dinâmica das faculdades que Kant apresenta na moralidade com a relação entre as faculdades no ajuizamento estético, tanto no belo quanto no sublime, presente na Crítica da faculdade do juízo. Nessa obra, a relação entre as faculdades do entendimento e da imaginação (no belo) e da razão com a imaginação (no sublime) nos revela que o sentimento de prazer e desprazer estéticos, ainda que sejam desinteressados, conduz o ânimo, por vias diversas, ${ }^{19}$ à "predisposição

\footnotetext{
${ }^{19}$ Por "vias diversas" quero referir-me à diferença entre o sentimento gerado no ajuizamento do belo e o sentimento gerado no sublime. Enquanto o primeiro é produzido em função de um acordo entre as faculdades cognitivas e a forma do objeto, o que nos faz sentir um prazer positivo que fortalece o ânimo sinalizando, com isso, a comunhão entre o ser humano e a natureza, o segundo só apraz mediante um "desacordo" entre as faculdades da imaginação e da razão o qual gera, inicialmente, um sentimento de desprazer, mas que, logo em seguida, produz um sentimento de prazer (negativo) em função de que o ser humano pode reconhecer aí a sua "destinação suprassensível" que é sua vocação à liberdade e à moralidade.
}

DIALEKTIKÉ, v. 1, novembro 2014, p. 29-49

Artigo submetido e aceito em outubro/2014 
à moralidade" ${ }^{20}$. O sentimento resultante do juízo estético é aí justificado por Kant como uma função da afinidade existente entre as faculdades que opera uma transposição sobre o "abismo" entre o domínio da natureza e o domínio da liberdade. Cito Kant:

A espontaneidade no jogo das faculdades de conhecimento, cujo acordo contém o fundamento deste prazer, torna o conceito pensado adequado para uma mediação da conexão dos domínios do conceito de natureza com o conceito de liberdade nas suas conseqüências, na medida em que este acordo promove ao mesmo tempo a receptividade do ânimo ao sentimento moral (CFJ, B LVII; p. 41).

\section{OS "MOTIVOS" DA RAZÃO PRÁTICA E OS EFEITOS DA LEI MORAL NO MUNDO}

Ainda que essa relação dinâmica entre as faculdades da razão seja uma das condições pelas quais não possamos considerar a moralidade como operando num nível puramente vazio, uma vez que afeta o ânimo (vida) do ser humano, essa relação entre as faculdades, por si só, não é suficiente para que possa haver a determinação da vontade pela razão. Segundo Kant, é preciso que haja algum "motivo" que sirva de "força motriz" para essa determinação, visto que a vontade humana, por não ser totalmente pura, não segue necessariamente uma lei da razão. ${ }^{21}$

\footnotetext{
${ }^{20}$ Segundo Kant, "o belo é o símbolo da moralmente-bom; e também somente sob este aspecto (uma referência que é natural a qualquer um e que também se exige de qualquer outro como dever) ele apraz com uma pretensão de assentimento de qualquer outro, em cujo caso o ânimo é ao mesmo tempo consciente de um certo enobrecimento e elevação sobre a simples receptividade de um prazer através de impressões dos sentidos e aprecia também o valor de outros segundo uma máxima semelhante de sua faculdade do juízo". Mais adiante Kant afirma que: "Nesta faculdade o juízo < die Urteilskraft $>$ não se vê submetido a uma heteronomia das leis da experiência, como de mais a mais ocorre no ajuizamento empírico; ela dá a si própria a lei com respeito aos objetos de uma complacência tão pura, assim como a razão o faz com respeito à faculdade de apetição; e ela vê-se referida, quer devido a esta possibilidade interna no sujeito, quer devido à possibilidade externa de uma natureza concordante com ela, a algo no próprio sujeito e fora dele que não é natureza e tampouco liberdade, mas que contudo está conectado com o fundamento desta, ou seja, o suprassensível no qual a faculdade teórica está ligada, em vista da unidade, com a faculdade prática de um modo comum < gemeinschaftlichen> e desconhecido" (CFJ, B 258-9, pp. 197-8).

${ }^{21}$ A esse respeito, Guido Antônio de Almeida nos esclarece que: "Assim, ainda que nossas escolhas dependam, por hipótese, de algum móvel sensível, dependerá de nosso arbítrio qual deles vai constituir o motivo, a "causa motriz" (Bewegungsgrund), como diz Kant, de nossa escolha. E assim também, embora possa ser verdade que nosso arbítrio dependa de um impulso sensível para ser accionado, nem por isso devemos dizer que ele é necessitado por esse impulso sensível, porque depende de seu consentimento que tal ou qual impulso determine sua escolha. (ALMEIDA, G. A. "Liberdade e Moralidade segundo Kant". In: Analytica, vol. 2 número 1, 1997. p. 185)
}

DIALEKTIKÉ, v. 1, novembro 2014, p. 29-49

Artigo submetido e aceito em outubro/2014 
No capítulo intitulado "Dos motivos da razão prática pura" da $C R P P^{22}$, o conceito de "motivo" (Triebfeder) ${ }^{23}$ é aí caracterizado por Kant como "o fundamento determinante subjetivo da vontade de um ente, cuja razão não é, já por sua natureza, necessariamente conforme à lei objetiva" ( $C R P r, \mathrm{~A} 127$; p. 249).

De um modo geral, podemos dizer que a grande questão, diga-se de passagem, sem resposta da filosofia prática de Kant é a que diz respeito ao fundamento da "motivação moral". Ainda que Kant tenha afirmado que a razão por si só pode determinar a vontade e, portanto, em função disso, pode ser uma razão prática pura, e mesmo que ele estivesse convencido de que a "representação pura da lei moral tem sobre o coração humano, pela via da razão apenas [...] um influxo tão mais poderoso do que todas as outras molas propulsoras que se possam mobilizar no campo estético [...]" (FMC; Ak 410-11, p. 177), na Crítica da razão prática, a despeito de todos os esforços e da essencialidade de tal questão, Kant se mostra convencido da dificuldade de se justificar o "motivo" de tal determinação, disso que ele chamou de um "problema insolúvel para a razão humana" ( $C R P r, \mathrm{~A} 128$; p.251). Talvez isso explique o fato de Kant ter deslocado a questão sobre o fundamento a partir do qual a representação da lei moral é o motivo suficiente na determinação da vontade humana, para uma questão que concerne mais ao modo operatório dessa lei, bem como aos efeitos que essa determinação causam no ânimo (vida) do ser humano. Cito Kant:

\begin{abstract}
“[...] assim não resta senão apenas determinar cuidadosamente de que modo a lei moral torna-se motivo e, na medida em que o é, que coisa acontece à faculdade de apetição humana enquanto efeito daquele fundamento determinante sobre a mesma lei. Pois o modo como uma lei pode ser por si e imediatamente fundamento determinante da vontade (o que com efeito é o essencial de toda a moralidade) é um problema insolúvel para a razão humana e idêntico à <questão>: como é possível uma vontade livre. Portanto não temos que indicar $a$ priori o fundamento a partir do qual a lei moral produz em si um motivo mas, na medida em que ela o é, o que ela efetiva (ou, para dizer melhor, tem de efetivar) no ânimo" (CRPr, A 128; p.251).
\end{abstract}

\footnotetext{
${ }^{22}$ CRPr, A 126 ; p. 246

23 A respeito da tradução de Triebfeder por "motivo", Valério Rohden nos dá um interessante esclarecimento: "[...] com base na dupla natureza humana, Triebfeder tomado como causa impulsiva divide-se em stimuli, que o homem segue em comum com os animais = arbitrium brutum, também chamado Triebfeder der Natur, e motiva = arbitrium liberum: 'Um motivum é sempre uma causa impulsiva moral'. Ele tem a ver diretamente com a razão e funda-se na capacidade de o homem determinar-se a si mesmo pela razão" (ROHDEN, V. Nota 119 da tradução na Crítica da razão prática, p. 583).
}

DIALEKTIKÉ, v. 1, novembro 2014, p. 29-49

Artigo submetido e aceito em outubro/2014 
Poderíamos reformular essa questão de modo a indicar, com isso, a viabilidade da nossa hipótese que é a relação entre a moralidade e o ânimo do ser humano partir da relação entre as faculdades e os efeitos da determinação moral na sensibilidade humana, naquilo que poderíamos chamar, agora, de "vivência moral". A questão, portanto, seria a seguinte: o que a realização da lei moral nos faz sentir? Se a lei moral nos faz sentir alguma coisa, isso já é um sinal da relação dinâmica entre as faculdades (razão, vontade e sensibilidade). Segundo, se a determinação moral tem algum efeito no mundo, esse efeito tem de ocorrer de acordo com um fim da razão que, por sua própria definição, é representado a priori.

Kant desloca, então, a questão sobre o fundamento a partir do qual a lei moral tem o seu motivo na determinação da vontade humana, para uma questão que concerne mais ao resultado do que ao fundamento: o que a lei moral efetiva ou tem de efetivar no ânimo (vida) do ser humano? (CRPr, A 128; p.251). E, mais ainda, qual é o seu efeito no mundo? Kant se pergunta sobre o que tal lei moral tem de realizar na vida do ser humano que se determinou a agir em função dessa lei, ou seja, Kant se pergunta em que consiste tal realização, qual é o seu fim? Se esse fim não visa um prazer pessoal, e, portanto, o seu valor não é retirado de nenhum móbil da experiência que supostamente agradaria aos sentidos, então resta-nos considerar que esse fim refere-se, antes de mais nada, ao que a lei representa em si mesma, de modo a razão ser capaz de dar origem a um sentimento de respeito ao valor absoluto que ela carrega. Se, todavia, podemos atribuir um valor à lei em si mesma, e se nossa razão é capaz de produzir um sentimento de respeito em relação a essa lei, é porque a lei, como uma lei da autonomia, é a expressão máxima do conceito de humanidade como "fim em si". A humanidade como "fim em si” é o que, segundo Kant, possui "valor absoluto".

Nosso questionamento a respeito da acusação de "formalismo vazio", com a qual sofreu e ainda sofre a proposta moral de Kant, argumenta porque tal acusação não se sustenta em face à inteira proposta de Kant. A primeira questão a ser feita a respeito dessa acusação de "formalismo vazio" é a seguinte: será que um fim que leva em conta o sentimento de respeito pela humanidade tanto em nós quanto nos outros pode ser considerado como "um formalismo vazio", que estaria distante da vida concreta do ser humano? Se a resposta for que poderia, então certamente será: ela comporta apenas uma "aprovação fria" e "sem vida". Mas, então, teriam de ser dadas as razões pelas quais um sentimento pode ser considerado algo frio e sem vida. Agora, se se leva seriamente em 
conta o que um sentimento significa, ou seja, se é levado em conta o "fato" e o seu "espírito" 24 , a realização da lei moral certamente comportará um entusiasmo pleno de vida, na medida em que na sua efetividade está o maior bem no mundo, inclusive como condição para a felicidade daquele que agiu moralmente e a dos demais.

Desse modo, ainda que não possamos "indicar a priori o fundamento a partir do qual a lei moral produz em si mesmo um motivo", podemos, não obstante, determinar com precisão o que a lei moral significa na vida humana, a partir dos seus efeitos e do seu fim que é a própria realização da virtude e com essa a própria ideia de humanidade.

\section{A VIVÊNCIA MORAL E A HUMANIDADE COMO "FIM EM SI MESMA"}

Se certos atos ainda podem nos chocar ao ponto de ajuizarmos que tais atos não deveriam acontecer, é porque há algo em nós que, independente do tempo em que nos encontramos, da nossa cultura e erudição, nos toca simplesmente por não corresponder ao fim da razão humana, da humanidade na pessoa de cada ser humano. Não é possível negar que nós ajuizamos nossos atos e os atos de outros seres humanos a partir de critérios racionais que despertam sentimentos de aversão ou de prazer quando as ações avaliadas se coadunam ou não com os fins da nossa razão. Tais juízos, em função de sua origem racional, nos remeteriam diretamente à questão: “O que é o ser humano?”. Nós nos perguntamos o que nós somos diante dos atos que nós praticamos. E isso pode ser um sinal de que a exigência racional por uma explicação plausível e suficiente seja uma das características da qual não possamos abrir mão.

Um ceticismo moral ou mesmo um relativismo ético, apanágios do nosso tempo, não satisfazem a razão humana que busca o incondicionado. Talvez isso explique o fato de porque Kant não aceitou admitir com Hume que a razão é "escrava das paixões". E se ele não pode aceitar isso, não foi por ter concluído que, ainda que sejamos movidos por nossos desejos e paixões, somos, ainda assim, capazes de agir diferentemente em função de outro fim, o qual pode nos dar um contentamento maior e mais duradouro. Se Kant não pode concordar com Hume, foi, sobretudo, porque Kant tinha clareza de que o seres humanos sempre voltam a se perguntar o por quê, a causa última, a condição ulterior de realizarem certas ações. E, no caso da afirmação de

${ }^{24} C R P r$, A $127 ;$ p. 249.

DIALEKTIKÉ, v. 1, novembro 2014, p. 29-49

Artigo submetido e aceito em outubro/2014 
Hume, Kant jamais poderia concordar posto que as paixões jamais poderiam explicar a incondicionalidade de uma ação. Assim, o fim incondicionado, isto é, um fim com valor absoluto, só pode ser uma exigência da razão. Tal coisa como incondicionada e, por isso mesmo, com valor absoluto, é a própria humanidade em cada pessoa. Daí ser em razão dessa busca de algo incondicionado para os nossos atos que sempre somos capazes de nos questionar diante dos mesmos, levando-nos a fazer a seguinte pergunta: "o que é o ser humano?".

Segundo Kant, uma vivência autêntica da moralidade pressupõe que os seres humanos queiram adotar máximas que orientem suas ações quando tais máximas puderem ser universalizadas. Desse pressuposto depende a consideração de que, no mundo, possa se efetivar a moralidade no conceito de um "reino dos fins" no qual os seres humanos ajam uns com os outros de acordo com um fim incondicional que é a própria humanidade em cada pessoa. Na medida em que os sujeitos elejam para si máximas pelas quais eles se perguntem como seria o mundo se todos pudessem adotar máximas semelhantes de modo a poder promover o maior bem no mundo.

Mas Kant afirma que é preciso querer agir de acordo com tais máximas. Agir segundo o "espírito da lei". Quando nos propomos a realizar alguma ação pelo "espírito" disso que queremos fazer, é porque consideramos que tal ação tem um sentido e um valor na nossa vida enquanto seres racionais e livres e, desse modo, podemos representar um sentimento de satisfação com a sua realização. Ao fazer isso, teríamos, portanto, um interesse pela lei. Kant define o interesse como sendo a "complacência que ligamos à representação da existência de um objeto" $\left(C F J, B\right.$; p.49) ${ }^{25}$. O objeto aqui é a realização da lei moral, a saber, o maior bem no mundo que é desejável por si mesmo e, inclusive é a própria condição da felicidade. Segundo Kant, "podemos tomar um interesse em algo sem por isso agir por interesse. O primeiro significa o interesse prático na ação, o segundo o interesse patológico da ação" (FMC, Ak 413[nota]; p. 187).

O interesse prático aí é o fim que o ser humano se coloca em função de sua racionalidade. No ser humano, o fim mais elevado que ele pode propor para sua vida consiste em que ele possa viver de uma forma autenticamente humana. Tal forma

\footnotetext{
${ }^{25}$ Kant apresenta outra definição para o conceito de interesse na FMC: “ A dependência, porém, de uma vontade contingentemente determinável de princípios da razão chama-se um interesse" (FMC, Ak 413[nota]; p. 187).
}

DIALEKTIKÉ, v. 1, novembro 2014, p. 29-49

Artigo submetido e aceito em outubro/2014 
autêntica da humanidade consistiria em que, ao fazer o maior uso possível da sua razão, o ser humano realizaria a sua liberdade ao adotar máximas universais cujo fim pudesse ser compatível com a liberdade dos outros seres humanos, alcançando desse modo, a dignidade de viver. Essa dignidade é acompanhada do sentimento de humanidade. Viver de acordo com o conceito de dignidade significa viver de acordo com um valor intrínseco. ${ }^{26}$ Esse valor intrínseco não é outro senão o respeito pela humanidade em nós mesmos e nós outros. Assim, perguntaríamos a nós mesmos se a máxima, segundo a qual decidimos agir, poderia ser adotada por todos, e, desse modo, como seria a vida no mundo se todos pudessem agir levando em conta uns aos outros como "fins em si mesmos".

Uma das fórmulas do Imperativo Categórico expressa exatamente esse conteúdo como fim da razão quando reza: Age de tal maneira que tomes a humanidade, tanto em tua pessoa, quanto na pessoa de qualquer outro, sempre ao mesmo tempo como um fim, nunca meramente como meio (FMC, Ak 429; p.243). E esse é igualmente um dos aspectos fundamentais pelos quais não podemos tomar a lei moral como um "vazio formalismo": na medida em que podemos considerar o respeito pela lei como sendo um respeito pela humanidade em nossa pessoa tanto quanto na pessoa de qualquer outro.

Quando Kant opõe a lei moral às inclinações, ele não está excluindo a dimensão sensível do ser humano de sua vida moral. A preocupação de Kant ao apartar as inclinações do fundamento da moralidade e afirmar que a lei moral é a única capaz de determinar a vontade, consiste em mostrar que as inclinações sensíveis podem levar a uma "autopresunção" e ao "amor de si" que acabam por ser obstáculos à realização da moralidade, chegando até mesmo a corrompe-la. Nas palavras de Kant:

Portanto a lei moral abate a presunção. Porém, visto que esta lei é algo em si positivo, a saber, a forma de uma causalidade intelectual, isto é, da liberdade, assim, na medida em que ela, em contraste com uma contra-atuação subjetiva, a saber, as inclinações em nós, enfraquece a presunção, é ao mesmo tempo um objeto de respeito e, na medida em que ela até a abate, isto é, a humilha, é um objeto do máximo respeito, por conseguinte também o fundamento de um sentimento positivo que não possui origem empírica e será conhecido a priori. Logo, o respeito pela lei moral é um sentimento produzido por um

${ }^{26}$ FMC, AK 435; p. 265.

DIALEKTIKÉ, v. 1, novembro 2014, p. 29-49

Artigo submetido e aceito em outubro/2014 
fundamento intelectual, e esse sentimento é o único que conhecemos de modo inteiramente a priori e de cuja necessidade podemos ter discernimento. (CRPr, A 130; p. 255) [grifos do autor].

O respeito, apesar de ser gerado na razão, pressupõe a sensibilidade, pois o seu efeito, como todo efeito sensível, só pode ser sentido na sensibilidade. Ele é, portanto, um sentimento eminentemente humano, pois depende tanto de se possuir a faculdade da razão quanto a faculdade do sentimento. E, já que o respeito pressupõe a sensibilidade e como essa é a marca da finitude humana, o respeito transpõe o ser humano em face ao seu limite, o coloca diante do seu limite entre uma obrigação racional e uma influência sensível. E é em função desse limite que a lei moral, segundo Kant, impõe respeito.

O respeito pela lei produzido pela razão indica, de modo mais fecundo, a relação entre as faculdades, uma vez que tal sentimento ainda que seja um produto da razão prática, encontra sua condição na sensibilidade, no sentimento, o que nos mostra que a moralidade não se constitui como um mero formalismo, uma vez que a sensibilidade, necessariamente, também é convidada a entrar em cena. Tal sentimento de respeito é, portanto, possibilitado pela relação entre as faculdades, como se elas realizassem um fim.

Outro ponto importante pelo qual não podemos concluir ser a moralidade proposta por Kant alijada de toda vida efetiva do ser humano consiste na sua doutrina do "sumo bem". Pelo fato de o princípio da lei moral ser um princípio formal, no sentido de não levar em conta a influência do objeto ou matéria das inclinações na determinação da vontade, a sua realização não exclui a possibilidade de uma relação com o sentimento de felicidade nos seres humanos. Ao contrário, após estabelecer que a lei moral é, por si só, o único fundamento de determinação da vontade, Kant aproxima a moralidade da vida sensível do ser humano na "doutrina do sumo bem" que é a felicidade em exata proporção com a moralidade. A lei moral, portanto, ainda que seja o único fundamento determinante de uma vontade verdadeiramente moral, não exclui a sensibilidade e a vida afetiva do ser humano da sua vida moral, pois, mesmo sendo o bem supremo, ou incondicional, a lei moral não é o "bem total" o qual corresponde à exata proporção entre moralidade e felicidade, nisso que Kant chama de "sumo bem”.

\section{CONSIDERAÇÕES FINAIS}

DIALEKTIKÉ, v. 1, novembro 2014, p. 29-49

Artigo submetido e aceito em outubro/2014 
Podemos pensar que o entusiasmo no seguimento da lei mosaica que Kant comparou com a comoção da lei moral, dá-se em função do limite desafiado à imaginação criadora de imagens. No caso da moralidade, é a vontade do ser humano que é desafiada pelas inclinações de sua natureza sensível a se determinar por uma lei da heteronomia, uma vez que a "vontade está bem no meio entre seu princípio a priori, que é formal, e sua mola propulsora a posteriori que é material, por assim dizer numa bifurcação [...]" (FMC, Ak 400; p. 127). Todavia, quando a vontade é determinada pela lei moral, o ânimo inteiro sente o efeito dessa determinação, como se a vida do ser humano fosse elevada à sua maior dignidade, exatamente por ter seguido uma lei da liberdade. Desse modo, quando o ser humano se priva de tudo aquilo que a lei recomenda, é a faculdade de apetição inferior que tem seus desejos prejudicados e não propriamente a vida, se a consideramos como faculdade capaz de se determinar por meio de representações da razão pura. É nesse sentido que nosso sentimento de vida não sai perdendo. E, visto que a lei moral prejudica as inclinações, poderíamos erroneamente considerar a lei como sendo um engodo, comportando apenas uma "aprovação fria" e sem "vida". Kant nos alerta ser uma "preocupação errônea supor que, se a gente se priva de tudo o que ela $<$ a lei> pode recomendar aos sentidos, ela então não comporte senão uma aprovação fria e sem vida e nenhuma força motriz ou comoção"(CFJ, B 125; p. 121).

O sentido da "força motriz" e da "comoção" da lei moral, portanto, pode ser vislumbrado, no limite do humano quando sua vontade, sendo desafiada pelas inclinações, ainda assim, numa dinâmica do todo da razão, se decide a agir por respeito à lei. ${ }^{27} \mathrm{E}$ a ausência de um conteúdo ou matéria da lei não depõe contra a mesma, mas antes constitui, para ela (para a lei), todo o teor de sua superioridade, em uma palavra, a sua sublimidade.

Ao fazermos esse breve percurso entre as notas fundamentais que envolvem a moralidade kantiana, podemos agora nos perguntar: qual é o ganho que obtivemos com tudo isso? Acreditamos que, ao lançar uma luz sobre a relação entre a lei moral e a

\footnotetext{
${ }^{27}$ Assim nos diz Kant: "[...] uma ação por dever deve por a parte toda a influência da inclinação e com ela todo objeto da vontade, logo nada resta para a vontade que possa determiná-la senão, objetivamente, a lei, e subjetivamente, $<0>$ puro respeito por essa lei prática, por conseguinte a máxima de dar cumprimento a uma lei mesmo com derrogação de todas as minhas inclinações (FMC, Ak 400-1; p. 128).
}

DIALEKTIKÉ, v. 1, novembro 2014, p. 29-49

Artigo submetido e aceito em outubro/2014 
vontade humana, podemos perceber que há muito mais na filosofia prática de Kant do que um "formalismo vazio".

Além disso, se, segundo Kant, é pela a consciência da coerção da lei moral sobre nós que podemos saber de nossa liberdade, o sentimento de respeito pela lei, que também tem a ver com essa consciência, nos leva a saber de nossa liberdade. Assim, como poderia ser uma representação fria e sem vida aquilo que nos leva à consciência de nossa liberdade? Como a liberdade não é passível de ser conhecida, a não ser a partir da coerção da lei moral, ou da consciência da lei moral ${ }^{28}$, disso podemos pensar que a "força motriz" ou a "comoção" dessa lei tem uma ligação profunda com a liberdade do ser humano na medida em que o efeito da lei na vontade humana é sentido como uma espécie de autorrealização por ter agido em função de suas próprias máximas. ${ }^{29}$ Por significar a expressão suprema da autonomia do ser humano e do respeito pela própria humanidade, como um fim da razão, é que a lei moral adquire um sentido muito especial na vida humana, sendo esse o fundamento ou o motivo que pode impulsionar a realização dessa mesma lei no querer humano para além de um suposto "formalismo vazio" de vida.

\section{REFERÊNCIAS}

ALLISON, Henry. Kant's theory of freedom. Cambridge: Cambridge University Press, 1990.

ALMEIDA, Guido Antônio: “Liberdade e Moralidade segundo Kant”. In: Analytica, vol. 2 número 1, 1997.

BECK, Lewis White: A commentary on Kant's Critique of Practical Reason. The Univ. of Chicago Press, 1960.

\footnotetext{
28 A esse respeito, numa nota inscrita no Prefácio à $C R P r$, Kant afirma que "a lei moral é a ratio cognoscendi da liberdade" (CRPr, A 5 ; p. 7). E, no primeiro livro dessa obra, intitulado "Analítica da razão prática pura", Kant afirma que "é a lei moral, da qual nos tornamos imediatamente conscientes ( tão logo projetamos para nós máximas da vontade), que se oferece primeiramente a nós e que, na medida em que a razão a apresenta como um fundamento determinante sem nenhuma condição sensível preponderante, antes, totalmente independente delas, conduz diretamente ao conceito de liberdade." (CRPr, A 53; p. 101).

${ }^{29}$ Valério Rodhen chama a atenção para o fato de que Kant não descurou de pensar a razão e suas ideias como dotada de uma potência de vida, à semelhança de uma árvore. Segundo Valério, "se as ideias expressam a vida da razão, o solo dessa vida é no homem a ideia de liberdade". ROHDEN V. "As ideias como formas de vida da razão" In: Was ist Der Mensch/ Que é o homem? Antropologia, Estética e Teleologia em Kant. Lisboa, CFUL, 2010, p. 337).
}

DIALEKTIKÉ, v. 1, novembro 2014, p. 29-49

Artigo submetido e aceito em outubro/2014 
BUENO, Vera Cristina Andrade: "A razão humana e a fundamentação da concepção teleológica da natureza". In, Was ist Der Mensch?/ O que é o homem? Antropologia, estética e Teleologia em Kant. Lisboa, CFUL, 2010, pp. 565-576.

CAFFARENA, José Gómez: "La Coherencia de la Filosofia Moral Kantiana". In Kant despues de Kant: En el Bicentenario de la Critica de la razon practica. Javier Muguerza Y Roberto Rodriguez Aramayo (Eds). Instituto de filosofia Del C.S.I.C.. Madrid, 1989, pp. 43-63.

CARNOIS, Bernard. La cohérence de la doctrine kantienne de la liberte. L'ordre philosophique. Paris, Éditions Du Seuil, 1976.

GARCÍA, Ramon Rodríguez: "El formalismo ético como lógica de la conciencia moral. In Kant despues de Kant: En el Bicentenario de la Critica de la razon practica. Javier Muguerza Y Roberto Rodriguez Aramayo (Eds). Instituto de filosofia Del C.S.I.C.. Madrid, 1989, pp. 76- 86.

GUYER, Paul: “A paixão pela razão: Hume, Kant e a motivação para a moralidade” In: O que nos faz pensar- Cadernos do Departamento de Filosofia da PUC-Rio. Edição especial sobre Kant; Org.: Vera Bueno, № 32, Dezembro de 2012.

HEGEL, G.W.F. Princípios da Filosofia do Direito. Tradução: Orlando Vitorino. Editora Martins Fontes: São Paulo, 1997

KANT, Immanuel. Fundamentação da Metafísica dos Costumes. Tradução: Guido Antônio de Almeida. Discurso Editorial e Barcarolla. São Paulo-SP, 2009

Crítica da razão prática. Edição Bilíngue. Tradução: Valério Rohden. Martins Fontes. São Paulo, 2003.

Crítica da faculdade do juízo. $2^{\mathrm{a}}$ edição. Trad. Valério Rohden e Antônio Marques. Forense Universitária. Rio de Janeiro: 2005.

Janeiro, 2006.

Lógica (Jäche). Trad. Guido de Almeida. Ed. Tempo Brasileiro: Rio de

Metafísica dos Costumes. Tradução: Clélia Aparecida Martins ( $1^{\mathrm{a}}$ parte); Bruno Nadai, Diego Kosbiau e Monique Hulshof (2 $2^{\mathrm{a}}$ parte). Ed. Vozes. Petrópolis, RJ, 2013.

MOLINER, Fernando Montero. "Libertad y experiencia: La fundamentacion de la libertad moral na critica da razão pura". In Kant despues de Kant: Em el Bicentenario de la Critica de la razon practica. Javier Muguerza Y Roberto Rodriguez Aramayo (Eds). Instituto de filosofia Del C.S.I.C.. Madrid, 1989, pp. 23-42.

ROHDEN, Valério. "As ideias como formas de vida da razão" In: Was ist Der Mensch/ Que é o homem? Antropologia, Estética e Teleologia em Kant. Lisboa, CFUL, 2010, PP.337-346. 
TUGENDHAT, E. Lições Sobre ética. $5^{\text {a }}$ edição revista. Trad. Joãosinho Beckenkamp e Cia. São Paulo: Editora Vozes, 2003.

WEBER, Thadeu. Ética e Filosofia Política: Hegel e o formalismo kantiano. EDIPUCRS, Porto Alegre, 1999.

WOOD Allen: "General Introduction". IN: KANT, I. Practical Philosophy. Translated and Edited by Mary J. Gregor. Cambridge University Press, 1996.

Kant. Tradução: Delamar José Volpato Dutra. Porto Alegre: Artmed, 2008. 